\title{
ARTICLE OPEN \\ Levels of exhaled carbon monoxide measured during an intervention program predict 1-year smoking cessation: a retrospective observational cohort study
}

\author{
Huei-Guan Shie ${ }^{1,2,3}$, Sheng-Wei Pan ${ }^{1,4}$, Wen-Kuang $\mathrm{Yu}^{1,4}$, Wei-Chih Chen ${ }^{1,4}$, Li-Ing Ho ${ }^{1,4}$ and Hsin-Kuo Ko
}

Life-long smoking cessation is a critical public health objective, but it is difficult for numerous people. This study aimed to identify the independent predictors of 1-year abstinence in smokers motivated to quit and participating in an intervention program. This 6year retrospective observational cohort study was conducted in smokers who participated in an intervention program. The exhaled carbon monoxide (CO) was sequentially measured on day 1, 8, 15, and 22 of the intervention program. The primary outcome measure was smoking status at 1 year of follow-up. A total of 162 participants were enrolled and divided into a successful quit group $(n=52)$ and unsuccessful quit group $(n=110)$. Using a multivariate logistic regression analysis, we reported that the intention to quit (adjusted odds ratio $[A O R]=1.475,95 \%$ confidence interval $[\mathrm{Cl}]=1.169-1.862, P$-value $=0.001$ ), varenicline use $(A O R=3.199,95 \% \mathrm{Cl}=1.290-7.934, P$-value $=0.012)$ and the exhaled CO level on day $8(\mathrm{AOR}=0.937,95 \% \mathrm{Cl}=0.885-0.992, P-$ value $=0.025$ ) independently predicted 1 -year smoking cessation. Moreover, the level of exhaled CO $<4.5$ parts per million on day 8 significantly predict successful 1 -year smoking cessation (area under curve 0.761 , sensitivity $88.2 \%$, and specificity $57.8 \%, P$-value $<0.001$ ). These independent predictors including intention to quit, varenicline use, and exhaled CO level on day 8 , may help primary care physicians rearrange resources and refine the strategies for intervention programs to achieve a higher rate of longterm smoking cessation.

npj Primary Care Respiratory Medicine (2017)27:59; doi:10.1038/s41533-017-0060-8

\section{INTRODUCTION}

Cigarette smoking is a modern-day epidemic that poses a substantial health burden and costs. ${ }^{1,2}$ In developed countries, cigarette smoking is the largest preventable cause of premature death and disability, ${ }^{3-6}$ and health risks associated with cigarette smoking may be reversed following a sufficient period of smoking cessation. ${ }^{7,8}$ Life-long smoking cessation is a critical public health objective while managing respiratory diseases in primary care, and smoking cessation is also crucial when managing all chronic diseases (e.g. hypertension and diabetes mellitus). Although both smoking cessation intervention programs and combined pharmacotherapy are effective in helping smokers quit, rates of 1-year sustained smoking cessation after the period of intervention are low (9.4-35.5\%). ${ }^{9-16}$ Quitting tobacco use is difficult for numerous people. Therefore, identifying independent predictors of smoking cessation in smokers motivated to quit and participating in an intervention program is crucial in helping primary care physicians identify smokers who might need more intensive treatments and health-care resources.

In general population samples of smokers, previous attempts to quit, age of smoking initiation, motivation to quit, nicotine addiction levels, self-efficacy levels, and preparatory planning have been identified as predictors of smoking cessation. ${ }^{17-25}$ In smokers participating in an intervention program, gender, selfefficacy levels, use of bupropion, and preparatory planning have been identified as predictors of short-term smoking cessation. ${ }^{22,26}$ However, predictors of long-term smoking cessation (e.g., a 1 year period) in this population remain largely unknown. Moreover, there is no objective biomarker being able to be measured during an intervention program and utilized to predict long-term smoking cessation. Consequently, it is difficult for physicians to develop an effective strategy for smoking cessation intervention programs. To our knowledge, the level of carbon monoxide (CO) in exhaled air is higher in healthy smokers than in non-smokers, and measuring the exhaled $\mathrm{CO}$ level is an immediate, and noninvasive method for assessing the smoking status. ${ }^{27,28}$ Whether the objective biomarker, exhaled $\mathrm{CO}$ level, measured in smokers during the period of participation in a group-orientated intervention program can predict 1-year smoking cessation remains unclear.

We conducted a retrospective observational cohort study to determine the independent predictors of sustained 1-year smoking cessation in smokers participating in a group-oriented smoking cessation program. We particularly focused on the role of exhaled $\mathrm{CO}$ measured during an intervention program in predicting long-term smoking cessation. The results of our study may help physicians to develop effective strategies for intervention program to increase the rate of long-term smoking cessation in primary respiratory care.

\footnotetext{
${ }^{1}$ Division of Respiratory therapy, Department of Chest Medicine, Taipei Veterans General Hospital, No. 201, Sec. 2, Shih-Pai Road, Taipei 112 , Taiwan, Republic of China; ${ }^{2}$ School of Respiratory Therapy, Taipei Medical University, Taipei, Taiwan, Republic of China; ${ }^{3}$ Division of Pulmonary Medicine, Department of Internal Medicine, Wan Fang Hospital, Taipei Medical University, Taipei, Taiwan, Republic of China and ${ }^{4}$ School of Medicine, National Yang-Ming University, Taipei, Taiwan, Republic of China Correspondence: Li-Ing Ho (liho@vghtpe.gov.tw) or Hsin-Kuo Ko (kuohsink@ms67.hinet.net)
}

Received: 16 July 2016 Revised: 7 September 2017 Accepted: 18 September 2017

Published online: 16 October 2017 


\section{RESULTS}

Demographic characteristics of study participants

During this 6-year study period, 202 consecutive smokers who participated in the smoking cessation program were reviewed. A total of 40 smokers were excluded because of (1) quitting smoking before the courses $(n=8)$, (2) failure to obtain complete information on their smoking status at 1, 3, 6, and 12 months of follow-up $(n=22)$, (3) failure to complete all smoking cessation courses $(n=10)$. In total, 162 smokers including 151 men and 11 women with a mean age 50.1 years $( \pm 17.1)$ were enrolled and analyzed in this study. The mean age of smoking initiation was $21.8( \pm 10.2)$ years, duration of smoking $30.2( \pm 15.8)$ years, and number of cigarette packs smoked per day 29.3 ( \pm 25.9 ). In total, 46 of 162 participants $(28.4 \%)$ used varenicline for more than 8 weeks. The overall rates of successful smoking cessation at the first, third, and sixth month, and 1 year of follow-up were 38.8, 37.0, 36.6, and $32.1 \%$, respectively.

Factors associated with the 1-year sustained smoking cessation All participants $(n=162)$ were divided into the unsuccessful quit $(n=110)$ and successful quit $(n=52)$ groups according to their smoking cessation status at 1 year of follow-up. The successful quit smokers were significantly associated with a higher mean score on the Likert scale of intention to quit (7.8 \pm 1.9 vs. $6.1 \pm 1.9$,
$P$-value $<0.001)$, and with a higher percentage of varenicline use (46.2 vs. $20.0 \%, P$-value $=0.001)$ compared with the unsuccessful quit smokers (Table 1).

The successful quit smokers exhibited lower levels of exhaled CO on day $8(6.6 \pm 7.3$ parts per million [ppm] vs. $14.7 \pm 13.0 \mathrm{ppm}$, $P$-value $<0.001)$, day $15(6.0 \pm 7.9 \mathrm{ppm}$ vs. $13.1 \pm 12.0 \mathrm{ppm}, P$-value $<0.001)$, and day $22(5.4 \pm 6.3$ ppm vs. $11.5 \pm 12.8$ ppm, $P$-value $<$ 0.001 ) compared with the unsuccessful quit smokers (Table 1, Fig. 1). The ROC curves were estimated for exhaled $\mathrm{CO}$ levels on day 1 , day 8 , day 15 , and day 22 (Fig. 2). A cutoff level for exhaled $\mathrm{CO}$ of $4.5 \mathrm{ppm}$ on day 8 exhibited the highest sensitivity and specificity in differentiating successful 1-year smoking cessation from unsuccessful cessation (area under curve $=0.761$, sensitivity $=88.2 \%$, specificity $=57.8 \%, \quad P$-value $<0.001)$. Therefore, the exhaled $\mathrm{CO}$ level on day 8 was used as a potential predictor in multivariate logistic regression analysis. No significant difference between the two groups was observed with respect to age, education level, baseline smoking status, comorbidity, addiction level, and pulmonary function values.

Independent predictors of 1-year sustained smoking cessation The predictors of successful 1-year smoking cessation in participants were further analyzed using multivariate logistic regression (Table 2). Significantly independent predictors of 1-year successful cessation were intention to quit (adjusted odds ratio

\begin{tabular}{|c|c|c|c|c|}
\hline Body mass index $\left(\mathrm{kg} / \mathrm{m}^{2}\right)$ & $24.3 \pm 3.3$ & $24.3 \pm 3.4$ & $24.3 \pm 3.1$ & 0.708 \\
\hline Male & $151(93.2)$ & $102(92.7)$ & $49(94.2)$ & 1.000 \\
\hline Age at starting smoking (yr) & $21.8 \pm 10.2$ & $22.3 \pm 10.5$ & $20.8 \pm 9.4$ & 0.112 \\
\hline Duration of cigarette smoking (yr) & $30.2 \pm 15.8$ & $30.7 \pm 15.1$ & $28.7 \pm 17.3$ & 0.504 \\
\hline Smoking (pack-yr) & $29.3 \pm 25.9$ & $30.7 \pm 15.1$ & $28.7 \pm 17.3$ & 0.504 \\
\hline \multicolumn{5}{|l|}{ Comorbidity } \\
\hline Asthma & $7(4.3)$ & $5(4.5)$ & $2(3.8)$ & 1.000 \\
\hline Intention to quit scale & $6.6 \pm 2.0$ & $6.1 \pm 1.9$ & $7.8 \pm 1.9$ & $<0.001$ \\
\hline Varenicline use & $46(28.4)$ & $22(20.0)$ & $24(46.2)$ & 0.001 \\
\hline \multicolumn{5}{|l|}{ Pulmonary function test } \\
\hline FEV1/FVC (\%) & $77.4 \pm 10.0$ & $77.1 \pm 10.6$ & $77.8 \pm 8.7$ & 0.726 \\
\hline FEV1(liter) & $3.1 \pm 0.8$ & $3.1 \pm 0.8$ & $3.2 \pm 0.8$ & 0.556 \\
\hline FEV1 (\% predicted) & $96.7 \pm 16.6$ & $96.5 \pm 17.1$ & $97.0 \pm 15.5$ & 0.989 \\
\hline FEF $25-75$ (\% predicted) & $71.4 \pm 30.1$ & $72.4 \pm 31.3$ & $69.4 \pm 30.4$ & 0.654 \\
\hline FEF $25-75 \%$ predicted $<80 \%$ & $104(64.2)$ & $67(60.9)$ & $37(71.2)$ & 0.291 \\
\hline \multicolumn{5}{|l|}{ Exhaled CO level (ppm) } \\
\hline On day $1(n=124)$ & $17.5 \pm 13.5$ & $18.9 \pm 14.3$ & $14.9 \pm 11.6$ & 0.107 \\
\hline
\end{tabular}



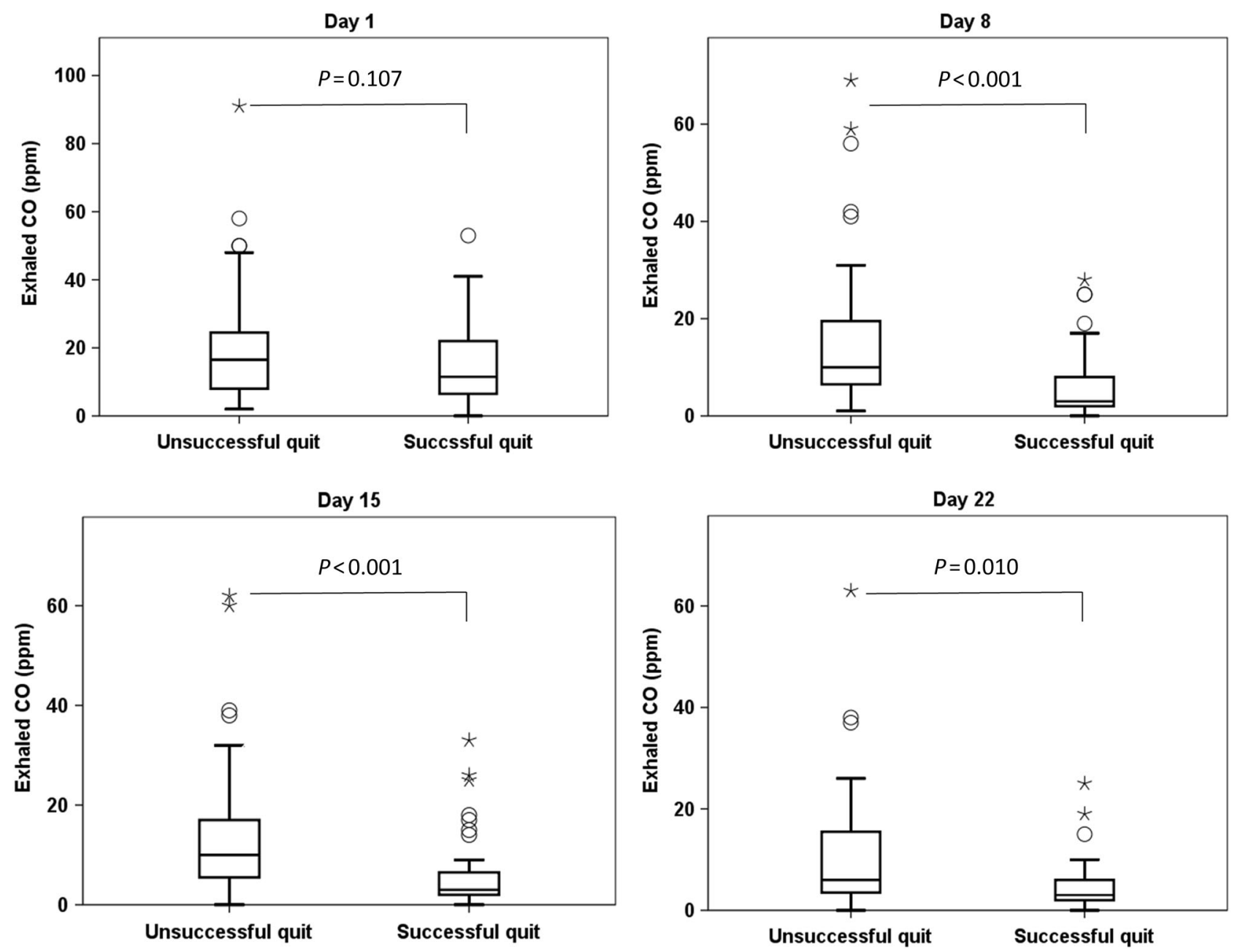

Fig. 1 Distribution of exhaled carbon monoxide on day $1(n=124)$, day $8(n=121)$, day $15(n=107)$, and day 22 ( $n=69)$ in smokers who quit unsuccessfully and those who quit successfully

$[\mathrm{AOR}]=1.475 ; 95 \%$ confidence interval $[\mathrm{Cl}]=1.169-1.862, P$-value $=0.001)$, varenicline use $(A O R=3.199,95 \% \mathrm{Cl}=1.290-7.934, P$ value $=0.012)$, and the exhaled $\mathrm{CO}$ level on day $8(\mathrm{AOR}=0.937$, $95 \% \mathrm{Cl}=0.885-0.992, P$-value $=0.025)$. Intention to quit, varenicline use, and the exhaled CO level on day 8 were also the independent predictors of successful smoking cessation after 1, 3, and 6 months of follow-up.

\section{DISCUSSION}

Main findings

In the present study, we found that intention to quit, varenicline use, and the exhaled CO level on day 8 to be independent predictors of 1-year sustained smoking cessation in motivated smokers who participated in a group-oriented intervention program. Meanwhile, a cutoff level of $4.5 \mathrm{ppm}$ for exhaled CO levels on day 8 that exhibited sensitivity of $88.2 \%$ and specificity of $57.8 \%$ could be considered as a useful biomarker in differentiating successful 1-year smoking cessation from unsuccessful cessation.

Interpretation of findings in relation to previously published work Common predictors of smoking cessation in clinical practice have been widely investigated and comprehensively reviewed. ${ }^{29}$ Several blood biomarkers have been reported to indicate smoking status, including nicotine, cotinine, or thiocyanate levels in the plasma or urine. ${ }^{30}$ Following cigarette smoke inhalation, CO displace oxygen in the erythrocyte to form carboxyhemoglobin $(\mathrm{COHb}) . \mathrm{CoHb}$ has a half-life of about $5-6 h^{31}$ and $\mathrm{CO}$ in alveolar air after breath holding is in equilibrium with the concentration of $\mathrm{COHb}$ in the blood. ${ }^{32}$ Middleton et al. report a significant correlation between breath $\mathrm{CO}$ and the number of cigarettes smoked in the last $24 \mathrm{~h}$, and several studies have reported a breath $\mathrm{CO}$ level more than $6-8 \mathrm{ppm}$ giving an appropriate sensitivity and specificity/selectivity to detect a smoker in outpatient clinics. ${ }^{27,28,30,33}$ In past, measuring the biomarker, exhaled CO level, was considered as an immediate, and noninvasive method for assessing smoking status and differentiating healthy smokers from nonsmokers. ${ }^{27,28}$ To our knowledge, there is no study reporting serial exhaled levels of $\mathrm{CO}$ measured in an intervention program to demonstrate the role of exhaled $\mathrm{CO}$ in predicting the long-term outcome of smoking cessation. In the present study, the levels of exhaled $\mathrm{CO}$ on day 1 , day 8 , day 15 , and day 22 were sequentially measured during the smoking cessation program. We observed that exhaled CO levels on day 1 of smoking cessation program were not significantly different between successful and unsuccessful quit groups. A cutoff level of $4.5 \mathrm{ppm}$ for exhaled CO levels on day 8 exhibited a sensitivity of $88.2 \%$ and a specificity of $57.8 \%$ to predict successful 1-year smoking cessation. Notably, intention to quit when attending a smoking cessation program was also an independent predictor of long-term smoking cessation. These findings of our study suggested that intention to quit was an early predictor and to measure exhaled $\mathrm{CO}$ level in smokers after the intervention 

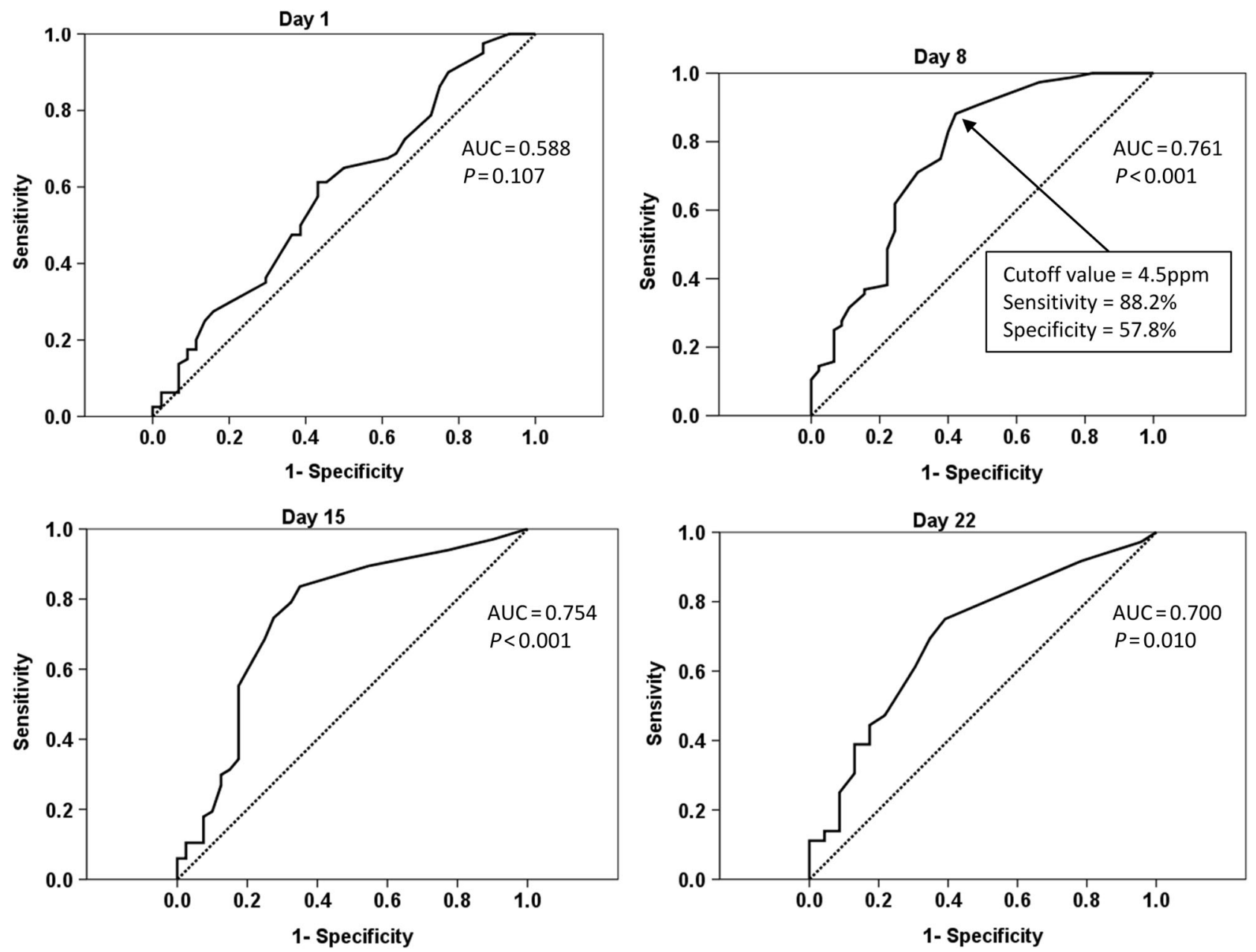

Fig. 2 Receiver operating characteristic curve analysis for exhaled carbon monoxide on day 1, day 8, day 15, and day 22 in study participants for determining the cutoff level for exhaled carbon monoxide with the highest sensitivity and specificity

program starts may well be a function of those who quit most rapidly and persistently. Results of the study can also be interpreted that people who are smoke free at least one week increase their success rate of smoking cessation.

Several factors have influence on the metabolism of $\mathrm{COHb}$ and exhaled levels of $\mathrm{CO}$. The half-life of $\mathrm{COHb}$ can be influenced by gender, physical activity, and ventilation rate, ${ }^{34-36}$ and impaired lung function affects the relationship between expired air $\mathrm{CO}$ and $\mathrm{COHb} .{ }^{32}$ Additionally, high levels of exhaled $\mathrm{CO}$ can be caused by environmental pollution, occupational exposure, passive smoking, active smoking, and airway inflammation in asthmatic lungs. ${ }^{37}$ In the current study, we enrolled subjects with a diagnosis of COPD and asthma $(33 / 162,20 \%)$ and reported the data of baseline lung function. We found that there was not statistical difference between unsuccessful and successful quit group among gender, data of lung function and the diagnosis of obstructive lung diseases. This finding may further confirm the generalization of applying exhaled CO level in predicting the outcome of long-term smoking cessation.

In total, $70 \%$ of smokers report that they want to quit; ${ }^{38}$ however, annually only $2-7 \%$ of smokers succeed. ${ }^{39,40}$ Pharmacotherapies and smoking cessation programs have been recommended by the World Health Organization as effective methods for motivated smokers to achieve higher rates of smoking cessation. $^{2}$ A combination of sustained-release bupropion and a nicotine patch was studied by Jorenby et al. in 893 smokers. Treatment with a combination of sustained-release bupropion and a nicotine patch yielded a significantly higher rate of smoking cessation at 12 months than did treatment with sustained-release bupropion, or a nicotine patch alone and a placebo alone (35.5, $30.3,16.4$ vs. $15.6 \%$, respectively). ${ }^{15}$ Varenicline, an agonist of the $\mathrm{a}_{4} \beta_{2}$ neuronal nicotinic acetylcholine receptor, is commonly used for facilitating smoking cessation. Koegelenberg et al. enrolled 446 smokers and blindly randomized them for either combination therapy with varenicline and a nicotine patch or varenicline monotherapy alone. ${ }^{41}$ The combination therapy exhibited significantly higher rates of continuous smoking cessation at 6 months ( 49.0 vs. $32.6 \%$ ) than the varenicline monotherapy did. Ebbert et al. analyzed combination therapy with varenicline and sustained-release bupropion in a randomized, blinded, controlled clinical trial and reported that the combination therapy did not significantly increase the rate of 1-year smoking cessation compared with varenicline monotherapy (30.9 vs. $24.5 \%){ }^{42}$ Additionally, smoking cessation programs with financial incentives have been studied to determine whether the interventions increase the rate of sustained smoking cessation compared with usual care. ${ }^{9,10}$ Halpern et al. concluded that the programs with financial incentives exhibited significantly higher rates of smoking cessation at 6 months than usual care did (9.4-16.0 vs. $6.0 \%) .{ }^{9}$ In the present study, the fee for the smoking cessation courses and varenicline use was covered by the Health Promotion Administration, Ministry of Health and Welfare, Taiwan. Physicians of our Department prescribed varenicline, and there was no participant receiving bupropion or nicotine replacement therapy (NRT) 
Table 2. Multivariate logistic regression analysis of potential predictors for smoking cessation at 1, 3, 6 month and 1 year of follow-up in the study subjects

\begin{tabular}{lllll}
\hline & 1-month successful quit & 3-month successful quit & 6-month successful quit & 1-year successful quit \\
\hline Intention to quit & 1.695 & 1.636 & 1.619 & 1.475 \\
& $(1.313-2.189)^{* *}$ & $(1.299-2.110)^{* *}$ & $(1.266-2.072)^{* *}$ & $(1.169-1.862)^{*}$ \\
Varenicline use & 5.975 & 6.278 & 4.496 & 3.199 \\
& $(2.128-16.777)^{*}$ & $(2.270-17.367)^{*}$ & $(1.688-11.969)^{*}$ & $(1.290-7.934)^{*}$ \\
Exhaled CO level onday 8 & 0.928 & 0.929 & 0.929 & 0.937 \\
& $(0.878-0.981)^{*}$ & $(0.877-0.984)^{*}$ & $(0.877-0.985)^{*}$ & $(0.885-0.992)^{*}$ \\
\hline $\begin{array}{l}\text { Data are reported as adjusted odds ratio }(95 \% \text { confidence interval) } \\
\text { CO carbon monoxide }\end{array}$ & & & \\
${ }^{*} P$-value $<0.05,{ }^{* *} P$-value $<0.001$ & & & \\
\hline
\end{tabular}

simultaneously during the period of smoking cessation program. Despite a low percentage of participants receiving a pharmacotherapy (varenicline use in $28.4 \%$ of study participants) and no financial incentive being offered in the smoking cessation program, a relatively high rate of 1 -year smoking cessation $(32.1 \%)$ was reported as compared with previous studies. ${ }^{9,10,41,42}$ Furthermore, the present study similarly showed that varenicline use was an independent predictor of long-term smoking cessation. The results of the present study and previous studies indicate that varenicline therapy is an effective combined pharmacotherapy during smoking cessation programs for increasing long-term smoking cessation.

Strength and limitations of this study

According to our review of relevant research, the present study is aimed to sequentially measure exhaled $\mathrm{CO}$ levels in smokers during a smoking cessation program and identify the biomarker of exhaled CO levels on day 8 as an independent predictor of longterm smoking cessation.

Our study has several limitations. First, it was a retrospective observational study. The measurement of exhaled $\mathrm{CO}$ is based on the willingness to accept and the number of smokers with measuring $\mathrm{CO}$ at each measurement point is declined. Some data are likely to be missing and cannot be recovered. Second, some participants were diagnosed with chronic obstructive pulmonary disease and asthma. The effect of chronic airway inflammation on the levels of exhaled $\mathrm{CO}$ in these smokers remains unclear. ${ }^{37,43}$ Third, self-reported smoking status at the time points of measuring exhaled $\mathrm{CO}$ is not recorded. The relationship between smoking cessation and exhaled CO levels after the program starts remains undefined. Finally, the results were originated from a population of motivated smokers who participated in a smoking cessation program. Whether the predictors of our study are applicable to all smokers and these findings can be generalized to all primary care patients remains unknown.

Implications for future research, policy, and practice

We reported that levels of exhaled CO were not only the indicator of current smoking status but also an independent predictor of long-term smoking cessation in motivated smokers. Meanwhile, a cutoff level of $4.5 \mathrm{ppm}$ of exhaled CO on day 8 can be used to differentiate successful 1-year smoking cessation from unsuccessful cessation (a sensitivity $=88.2 \%$, and specificity $=57.8 \%$ ). The biomarkers of exhaled CO may provide primary care physicians with the critical and immediate information required to rearrange resources, change policy and refine the strategies for intervention programs to achieve a higher rate of long-term smoking cessation. Whether our findings could actually assist in the clinician's decision making, and the concept of exhaled CO levels as the objective biomarker to rearrange the medical resource deserve to be prospectively investigated and validated in future researches.

\section{CONCLUSIONS}

In motivated smokers participating in a group-oriented smoking cessation program, intention to quit, varenicline use, and the exhaled CO level on day 8 independently predict 1-year smoking cessation. A cutoff level of 4.5 ppm for exhaled CO on day 8 of the intervention program exhibits the highest sensitivity and specificity in differentiating 1-year successful smoking cessation and unsuccessful cessation. Main conclusion is that intention to quit and use of varenicline is the strongest predictor for 1-year successful quit and this is also in agreement with other studies.

\section{METHODS}

Study design and smoking cessation intervention program A retrospective observational cohort study was conducted at Taipei Veterans General Hospital, a tertiary medical center in Taiwan. Regular smokers were targeted for recruitment, and no financial incentives were offered for participating in the group-oriented intervention program. A multifaceted recruitment scheme was used to enroll hospital employees, or their relatives and friends, and participants through advertisements on the website of Taipei Veterans General Hospital. The same smoking cessation program over the study period and instructors of the smoking cessation courses were approved by the Health Promotion Administration, Ministry of Health and Welfare, Taiwan, ROC. The 22-day smoking cessation program comprised four smoking cessation courses ( $3 \mathrm{~h}$ per course, $12 \mathrm{~h}$ in total). Medications for smoking cessation, sustained-release bupropion and varenicline, and NRT were prescribed by pulmonologists of the Department of Chest Medicine according to the needs of participants during the period of the smoking cessation courses. The study was approved by the Institutional Ethical Review Board of Taipei Veterans General Hospital (VGHTPE-IRB No. 2015-08-001CE), and Informed consent was waived under the approval of the VGHTPE-IRB according to the institutional guideline for a retrospective observational study. Methods were performed in accordance with relevant regulations and guidelines.

\section{Study participants}

Smokers who attempted to quit smoking and participated in the intervention program for smoking cessation at the Department of Chest Medicine of Taipei Veterans General Hospital between July 2008 and June 2014 were reviewed. Participants were excluded, if (1) they had stopped cigarette smoking within 1 month before participating in the smoking cessation courses, (2) they were not able to complete the smoking cessation courses, and (3) the information on their smoking status at 1, 3, 6, and 12 months of follow-up was not obtained. The enrolled smokers were divided into successful and unsuccessful 1-year sustained quit groups according to their smoking status 12 months after completing all four smoking cessation courses. 


\section{Baseline measurements}

The departmental log was used to identify the participants, and the following demographic information was collected through a careful chart review by using a specifically designed data sheet: age, sex, marital status, height, body weight, education level, comorbidity, respiratory system symptoms, and the history of cigarette smoking (numbers and years). Medications, namely SR bupropion and varenicline, and NRT were reviewed carefully and recorded. The addiction level was measured using the abbreviated Fagerström Test for Cigarette Dependence $(0=$ not addicted, $10=$ highly addicted). ${ }^{44,45}$ Intention to quit smoking was measured on a 10-point likert scale by asking the participant whether or not he or she intended to quit smoking $(1=$ very certainly not; $10=$ very certainly yes).

\section{Follow-up measurements}

A pulmonary function test was conducted within 1 week after participation in the smoking cessation program. The exhaled $\mathrm{CO}$ levels of the participants were measured using a MicroCO meter (CareFusion, CA, USA) on day 1 , day 8 and day 15 , and day 22 of smoking cessation program. The smoking status at the 12th month of follow-up after the completion of the smoking cessation courses was set as the primary outcome measure. Furthermore, the self-reported smoking status at the first month, third month, sixth month, and twelfth month of follow-up by interviewing the participants by phone. Successful 1-year smoking cessation was achieved when a participant reported not smoking since the completion of the smoking cessation courses.

\section{Statistical analysis}

All data were expressed as the mean \pm standard deviation or as a percentage (\%). Categorical variables were compared using the chisquared test or Fisher's exact test. Regarding numerical variables, the Mann-Whitney $U$ test was used for non-normally distributed variables, and the independent $t$-test was used for normally distributed variables. Variables exhibiting significant differences between the two groups $(P$ value $<0.05)$ were subjected to multivariate forward stepwise logistic regression analysis to determine factors independently associated with successful smoking cessation at 1, 3, 6 months, and 1 year. Receiver operating characteristic (ROC) curve analysis was used to identify optimal cutoff points for creating dichotomous variables. All statistical analyses were conducted using SPSS, version 19.0 (SPSS Inc., Chicago, IL, USA). The results were considered significant at a two-sided $P$-value $<0.05$.

Data availability statement

The data that support the findings of this study are available from the corresponding author upon reasonable request.

\section{ACKNOWLEDGEMENTS}

The authors thank all instructors for their valuable contribution to the smoking cessation program. The authors are grateful to Victor Douglas and Vincent Katona of Wallace Academic Editing for their help with language editing.

\section{AUTHORS CONTRIBUTIONS}

All the authors were involved in the planning, design, statistical analysis of the study, and in writing the manuscript.

\section{ADDITIONAL INFORMATION}

Competing interests: The authors declare no competing financial interests.

Publisher's note: Springer Nature remains neutral with regard to jurisdictional claims in published maps and institutional affiliations.

\section{REFERENCES}

1. US Department of Health and Human Services. The Health Consequences of Smoking: A Report of the Surgeon General (US Department of Health and Human Services, Centers for disease control and prevention, National Centre for Chronic Disease Prevention and Health Promotion, Office on Smoking and Health, Atlanta, 2004).
2. Raw, M. et al. WHO Europe evidence based recommendations on the treatment of tobacco dependence. Tob. Control 11, 44-46 (2002).

3. Danaei, G. et al. The preventable causes of death in the United States: comparative risk assessment of dietary, lifestyle, and metabolic risk factors. PLoS Med. 6, e1000058 (2009).

4. Ikeda, N. et al. Adult mortality attributable to preventable risk factors for noncommunicable diseases and injuries in Japan: a comparative risk assessment. PLoS Med. 9, e1001160 (2012).

5. Rostron, B. L., Chang, C. M. \& Pechacek, T. F. Estimation of cigarette smokingattributable morbidity in the United States. JAMA Intern. Med. 174, 1922-1928 (2014).

6. Edwards, R. The problem of tabacco smoking. BMJ 328, 217-219 (2004).

7. Centers for Disease Control and Prevention. The Health Benefits of Smoking Cessation: A Report of the Surgeon General. http://profiles,nlm.nih.gov/NN/B/B/C/T/. Accessed 1 Oct 2015 (1990).

8. Centers for Disease Control and Prevention. Women and Smoking: A Report of the Surgeon General. http://www/surgeongeneral.gov/library/womenandtobacco/. Accessed 1 Oct 2015 (2001).

9. Halpern, S. D. et al. Randomized trial of four financial-incentive programs for smoking cessation. N. Engl. J. Med. 372, 2108-2117 (2015).

10. Volpp, K. G. et al. A randomized, controlled trial of financial incentives for smoking cessation. N. Engl. J. Med. 360, 699-709 (2009).

11. Costello, M. J. et al. Effectiveness of pharmacist counseling combined with nicotine replacement therapy: a pragmatic randomized trial with 6,987 smokers. Cancer Causes Control 22, 167-180 (2011).

12. Baker., A. et al. A randomized controlled trial of a smoking cessation interventiomps@1n among people with a psychotic disorder. Am. J. Psychiatry 163, 1934-1942 (2006).

13. Simon, J. A., Carmody, T. P., Hudes, E. S., Snyder, E. \& Murray, J. Intensive smoking cessation counseling versus minimal counseling among hospitalized smokers treated with transdermal nicotine replacement: a randomized trial. Am. J. Med. 114, 555-562 (2003).

14. Boutou, A. K. et al. Smoking cessation in clinical practice: predictors of six-month continuous abstinence in a sample of Greek smokers. Prim. Care Respir. J. 17, 32-38 (2008).

15. Jorenby, D. E. et al. A controlled trial of sustained-release bupropion, a nicotine patch, or both for smoking cessation. N. Engl. J. Med. 340, 685-691 (1999).

16. Tashkin, D. et al. Smoking cessation in patients with chronic obstructive pulmonary disease: a double-blind, placebo-controlled, randomised trial. Lancet 357, 1571-1575 (2001)

17. Hyland, A. et al. Individual-level predictors of cessation behaviours among participants in the International tobacco control (ITC) four country survey. Tob. Control 15(suppl. 3), iii83-iiig4 (2006).

18. Murray, R. P. et al. Characteristics of participants who stop smoking and sustain abstinence for 1 and 5 years in the lung health study. Prev. Med. 30, 392-400 (2000).

19. Lando, H. A. et al. Age of initiation, smoking patterns, and risk in a population of working adults. Prev. Med. 29, 590-598 (1999).

20. Vangeli, E., Stapleton, J., Smit, E. S., Borland, R. \& West, R. Predictors of attempts to stop smoking and their success in adult general population samples: a systematic review. Addiction 106, 2110-2121 (2011).

21. Diemert, L. M., Bondy, S. J., Brown, K. S. \& Manske, S. Young adult smoking cessation: predictors of quit attempts and abstinence. Am. J. Public Health 103, 449-453 (2013).

22. Elfeddali, I., Bolman, C., Candel, M. J., Wiers, R. W. \& de Vries, H. The role of selfefficacy, recovery self-efficacy, and preparatory planning in predicting short-term smoking relapse. Br. J. Health Psychol. 17, 185-201 (2012).

23. Dale, L. C. et al. Bupropion for smoking cessation: predictors of successful outcome. Chest 119, 1357-1364 (2001).

24. Harris, K. J. et al. Predictors of smoking cessation among African-Americans enrolled in a randomized controlled trial of bupropion. Prev. Med. 38, 498-502 (2004).

25. Stapleton, J. A. et al. Dose effects and predictors of outcome in a randomized trial of transdermal nicotine patches in general practice. Addiction 90, 31-42 (1995).

26. Smit, E. S., Hoving, C., Schelleman-Offermans, K., West, R. \& de Vries, H. Predictors of successful and unsuccessful quit attempts among smokers motivated to quit. Addict. Behav. 39, 1318-1324 (2014).

27. Deveci, S. E., Deveci, F., Açik, Y. \& Ozan, A. T. The measurement of exhaled carbon monoxide in healthy smokers and non-smokers. Respir. Med. 98, 551-556 (2004).

28. Middleton, E. T. \& Morice, A. H. Breath carbon monoxide as an indication of smoking habit. Chest 117, 758-763 (2000).

29. Caponnetto, P. \& Polosa, R. Common predictors of smoking cessation in clinical practice. Respir. Med. 102, 1182-1192 (2008). 
30. Jarvis, M. J., Tunstall-Pedoe, H., Feyerabend, C., Vesey, C. \& Saloojee, Y. Comparison of tests used to distinguish smokers from nonsmokers. Am. J. Public Health 77, 1435-1438 (1987).

31. Peterson, J. E. \& Stewart, R. D. Absorption and elimination of carbon monoxide by inactive young men. Arch. Environ. Health 21, 165-171 (1970).

32. Jarvis, M. J., Russell, M. A. \& Saloojee, Y. Expired air carbon monoxide: a simple breath test of tobacco smoke intake. BMJ 281, 484-485 (1980).

33. Crowley, T. J., Andrews, A. E., Cheney, J., Zerbe, G. \& Petty, T. L. Carbon monoxide assessment of smoking in chronic obstructive pulmonary disease. Addict. Behav. 14, 493-502 (1989).

34. Deller, A., Stenz, R., Forstner, K. \& Konrad, F. The elimination of carboxyhaemoglobin: gender specific and circadian effects. Infusionsther. Transfusionsmed. 19, 121-126 (1992).

35. Joumard, R., Chiron, M., Vidon, R., Maurin, M. \& Rouzioux, J. M. Mathematical models of the uptake of carbon monoxide on hemoglobin at low carbon monoxide levels. Environ. Health Perspect. 41, 277-289 (1981).

36. Vesley, A. et al. Effect of ventilation on carbon monoxide clearance in humans [abstract]. Am. J. Respir. Crit. Care Med. 159, A767 (1999).

37. Zayasu, K. et al. Increased carbon monoxide in exhaled air of asthmatic patients. Am. J. Respir. Crit. Care Med. 156, 1140-1143 (1997).

38. US Centers for Disease Control and Prevention. Cigarette smoking among adults -United States, 2000. MMWR Morb. Mortal. Wkly. Rep. 51, 642-645 (2002).

39. US Centers for Disease Control and Prevention. Tobacco use among adults - United States, 2005. MMWR Morb. Mortal. Wkly. Rep. 55, 1145-1148 (2006).

40. Fiore, M. C. et al. A clinical practice guideline for treating tobacco use and dependence: a US public health service report. The tobacco use and dependence clinical practice guideline panel, staff, and consortium representatives. JAMA $\mathbf{2 8 3}$, 3244-3254 (2000).
41. Koegelenberg, C. F. et al. Efficacy of varenicline combined with nicotine replacement therapy vs varenicline alone for smoking cessation: a randomized clinical trial. JAMA 312, 155-161 (2014).

42. Ebbert, J. O. et al. Combination varenicline and bupropion SR for tobaccodependence treatment in cigarette smokers: a randomized trial. JAMA 311, 155-163 (2014).

43. Chatkin, G. et al. Evaluation of the exhaled carbon monoxide levels in smokers with COPD. J. Bras. Pneumol. 36, 332-338 (2010).

44. Fagerstrom, K. Determinants of tobacco use and renaming the FTND to the fagerstrom test for cigarette dependence. Nicotine Tob. Res. 14, 75-78 (2012).

45. Heatherton, T. F., Kozlowski, L. T., Frecker, R. C. \& Fagerstrom, K. O. The fagerstrom test for nicotine dependence: a revision of the fagerstrom tolerance questionnaire. Br. J. Addict. 86, 1119-1127 (1991).

(i) Open Access This article is licensed under a Creative Commons Attribution 4.0 International License, which permits use, sharing, adaptation, distribution and reproduction in any medium or format, as long as you give appropriate credit to the original author(s) and the source, provide a link to the Creative Commons license, and indicate if changes were made. The images or other third party material in this article are included in the article's Creative Commons license, unless indicated otherwise in a credit line to the material. If material is not included in the article's Creative Commons license and your intended use is not permitted by statutory regulation or exceeds the permitted use, you will need to obtain permission directly from the copyright holder. To view a copy of this license, visit http://creativecommons org/licenses/by/4.0/.

(c) The Author(s) 2017 